\title{
EDUCAÇÃO POPULAR FEMININA: UMA ANÁLISE EM ENRIQUE DUSSEL SOBRE A LIBERTAÇÃO DA MULHER EM MEIOS RURAIS NA PRIMEIRA METADE DO SÉCULO XX
}

\author{
Paula Simone Busko* \\ lattes.cnpq.br/3407712984691685
}

\begin{abstract}
Resumo: Este artigo traz uma reflexão teórica a respeito dos caminhos da mulher analfabeta que consegue a libertação por meio da educação popular. Trazendo uma abordagem em torno dos conceitos de libertação do filósofo Enrique Dussel, este texto prioriza práticas de educação popular em meios carentes. Metodologicamente, sob o olhar de Enrique Dussel, este caminhar reflete a busca da mulher como forma de libertação ao meio culturalmente e socialmente opressor, no intuito de se desvencilhar de uma consciência subalternizada pelo colonialismo. Neste despertar e neste encontro consigo mesma, a mulher que consegue se libertar por meio de uma educação popular recria seus caminhos. Conclui-se que os investimentos na alfabetização para as mulheres trazem retornos sociais altos: melhora a saúde das famílias e traz uma conscientização do dever de motivar seus filhos também a estudar. Mulheres recém-alfabetizadas melhoram os indicadores de desenvolvimento e, portanto, todos os cidadãos, instituições e organismos governamentais deveriam estar comprometidos para a alfabetização destas mulheres que tanto tem sofrido com a opressão ao longo da história.
\end{abstract}

Palavras-chave: Educação popular; Mulher; Libertação; Enrique Dussel.

\section{FEMALE POPULAR EDUCATION: AN ANALYSIS IN ENRIQUE DUSSEL ON LIBERATION WOMAN IN RURAL MEDIA IN THE FIRST HALF OF THE TWENTIETH CENTURY}

\begin{abstract}
This article brings a theoretical reflection on the ways of the illiterate woman who obtains the liberation through the popular education. Bringing an approach around the concepts of liberation of the philosopher Enrique Dussel, this text prioritizes practices of popular education in needy environments. Methodologically, under the watchful eye of Enrique Dussel, this walk reflects the search of the woman as a way of liberation to the environment culturally and
\end{abstract}

\footnotetext{
* Doutoranda em Educação Científica e Tecnológica na Universidade Federal de Santa Catarina (Brasil). Contato: paulabusko@gmail.com.
} 
socially oppressive, in order to get rid of a conscience subalternizada by colonialism. In this awakening and in this encounter with herself, the woman who is able to free herself through a popular education recreates her ways. It is concluded that investments in literacy for women bring high social returns: it improves the health of families and brings an awareness of the duty to motivate their children to study. Newly literate women improve development indicators and therefore all citizens, institutions and government agencies should be committed to the literacy of these women who have suffered so much from oppression throughout history.

Palavras-chave: Popular education; Woman; Liberation; Enrique Dussel.

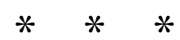

\section{Introdução}

Este artigo traz uma reflexão teórica a respeito dos caminhos da mulher analfabeta que consegue a libertação por meio da educação popular. Trazendo uma abordagem em torno dos conceitos de libertação do filósofo Enrique Dussel, este texto prioriza práticas de educação popular em meios carentes. Como parte de uma pesquisa em doutoramento em educação científica e tecnológica, a educação popular aponta para o ensino das ciências básicas, além das primeiras letras, com o objetivo de entrelaçar mulher, educação popular e o ensino de ciências em meios rurais. Metodologicamente, sob o olhar de Enrique Dussel ${ }^{1}$, este caminhar reflete a busca da mulher como forma de libertação ao meio culturalmente e socialmente opressor, no intuito de se desvencilhar de uma consciência subalternizada pelo colonialismo. Especificamente, este trabalho está voltado sobre as ações sociais de educação popular de mulheres pobres e analfabetas

\footnotetext{
${ }^{1}$ Enrique Dussel, (Mendoza, Argentina, 24 de dezembro de 1934-) é um filósofo argentino radicado (exilado) desde 1975 no México. É um dos maiores expoentes da Filosofia da Libertação e do pensamento latino-americano. Seu pensamento discorre sobre temas como: filosofia, política, ética e teologia.
} 
localizadas no litoral sul de São Paulo e o Vale do Ribeira onde diversos movimentos de educação se fazem presentes.

No Brasil de hoje, a condição da mulher excluída socialmente, sobretudo da educação, tem sido palco de discussões, desde os meios acadêmicos em seus vários campos do saber até no que diz respeito às políticas públicas. Nos meios rurais, tais políticas ainda caminham de maneira tímida, na medida em que as pesquisas voltadas para a condição da mulher no campo trazem à tona novos sujeitos, enfatizando a importância da representação feminina em espaços subalternizados pelo colonialismo.

A educação popular feminina tem sido tema de várias pesquisas e eventos e abordam não somente a questão da alfabetização, mas também assuntos relacionados ao mundo do trabalho, meio ambiente, direitos humanos e saúde da família. Está certo que a situação da mulher oprimida perdura por gerações. A própria família, a escola, a Igreja e o Estado não colaboraram para que este quadro mudasse e as próprias mulheres se colocaram a dispor deste pensamento medieval. A história da exclusão social da mulher não é recente, mas sem dúvida, é a história de uma luta: na busca de seu próprio reconhecimento e de ser reconhecida como ser capaz de tomar suas próprias decisões e seguir o caminho de suas escolhas.

Imprescindível é dialogar acerca de estudos e reflexões da condição da mulher brasileira, desprovida de recursos financeiros e do aprendizado escolar, subjugada em seu meio, e de como esta mulher poderá se libertar, através de uma educação popular, de acordo com os conceitos de libertação de Enrique Dussel.

Os estudos de Dussel sobre a filosofia da libertação viabilizam os caminhos para que se forme uma nova estética da libertação destas mulheres, de forma intencional e racional. Através da responsabilidade e o respeito pela dignidade da mulher, antes de tudo como ser humano, novas formas de ensino voltadas para um futuro não mais opressor e não sexista se reconciliam com as novas formas de pensar e agir. Além disso, a própria Igreja católica procura redirecionar seu papel social e político em resposta aos questionamentos so- 
ciais diante da modernização e do trabalho e de várias mulheres que se exteriorizaram e buscaram sua liberdade, a exemplo das teólogas feministas que surgiram no século XX. A Teologia Feminista é um ramo dentro da conhecida Teologia da Libertação, as aplicações dos princípios da libertação são direcionados para defender as mulheres desfavorecidas num ambiente predominantemente masculino.

Esta pesquisa traz em seu arcabouço teórico documentos e memórias. A história oral também deve ser entendida como uma experiência humana, de determinado grupo social. Estas experiências serão recuperadas agora com "um novo olhar", com o intuito de alimentar o presente e o futuro. Faz-se necessário conhecer os caminhos traçados pelas mulheres inseridas nestas comunidades para que se conheça não somente o que está sendo representado por elas, mas por que está sendo representado daquela forma.

Daí a importância dos estudos do gênero feminino e da educação para mulheres, além de como a Igreja católica interferiu nos modos de vida de mulheres dos meios rurais por meio da educação e de como estas se organizaram em suas comunidades. Sem dúvida, elas passaram por um processo de disciplinarização que permeou toda a atividade social do grupo, desde as festividades até a família e o trabalho. Neste sentido, conhecer as maneiras de como uma comunidade se organiza significa conhecer os modos de poder envolvidos no processo. Em contrapartida, as mulheres também modificaram o processo social na qual estavam inseridas (pressões determinantes), trazendo a importância da singularidade dos sujeitos em suas práticas sociais.

Estudos e movimentos de educação popular surgem com elevada importância a partir do século XX, como os que abrangem a situação da mulher na América Latina, a exemplo da Comissão Econômica para a América Latina e o Caribe (CEPAL) e em nível local, como por exemplo, o movimento da Assistência ao Litoral de Anchieta (A.L.A.), que ocorreu na primeira metade do século XX no litoral sul paulista. Tais movimentos devem ser motivados para que seus participantes dentro deste processo de mudança adquiram a forma- 
ção de uma consciência autônoma, potencializando novas formas de viver na sociedade, no trabalho nas práticas sociais.

\section{A mulher rural e a Educação popular feminina}

A relação entre a educação popular feminina e pobreza não é um tema recente. A partir de 1990, algumas agências multilaterais a exemplo do Banco Mundial e a Cepal trouxeram debates sobre a importância da condição social da mulher e de como a erradicação da pobreza poderia ser combatida através da educação. Muitas mulheres ainda encontram enorme dificuldade de acesso à escola e sofrem discriminação étnica e de gênero, como por exemplo, na questão salarial. As mulheres "[...] enfrentam toda sorte de obstáculos culturais, sociais, legais e econômicos que os homens, inclusive os pobres, não têm." (BANCO MUNDIAL, 1990, p. 35).

Traduzindo em números, o mundo possui cerca de 6,5 bilhões habitantes. Segundo a UNESCO 2796 milhões de pessoas são analfabetas, dentre os quais 530 milhões mulheres. No Brasil, primeiro no ranking da América Latina a possuir maior número de analfabetos, cerca de 14 milhões são analfabetos, dados do Instituto Brasileiro de Geografia e Estatística (IBGE), e de acordo com os dados do Instituto de Estudos Socioeconômicos (Inesc), órgão não governamental que realizou uma pesquisa para o Tribunal Superior Federal, cerca de 4,5 milhões são mulheres e 3,8 são homens dos brasileiros considerados aptos a votar.

As políticas sociais de combate à pobreza não fogem dos estudos relacionados ao gênero feminino, pois que através da mulher o "ciclo da pobreza" poderia ser, aos poucos, superado. Portanto, uma das maneiras mais eficazes de combater a pobreza seria trazer para estas mulheres diversos tipos de conhecimento, por exemplo, saúde

2 United Nations Educational, Scientific and Cultural Organization (UNESCO), órgão ligado a Organização das Nações Unidas (ONU). 
familiar, no trato com crianças e controle de natalidade, uma vez a mulher com maior instrução poderá se casar com mais idade e usar métodos anticonceptivos. O conhecimento das letras neste contexto é fundamental, porque estariam relacionadas a benefícios sociais mais amplos, as oportunidades de trabalho e aos direitos de cidadã. O combate à pobreza, através da educação feminina, coloca a mulher como centro de algumas questões sociais "[...] nos assuntos ligados à moradia e ao bairro, seja ainda pela presença significativa de mulheres entre a população pobre" (FARAH, 2004, p. 55).

As diferenças de gênero evidenciadas em nossa sociedade ocorrem muito mais por falta de escolaridade das mulheres frente aos homens do que diferenças consideradas de ordem religiosa ou biológica:

Segundo as abordagens de gênero, as diferenças nos níveis educacionais não decorrem de características biológicas, mas sim das condições históricas e estruturais da conformação de cada sociedade. Em quase todos os países do mundo as mulheres sempre tiveram maiores barreiras no acesso à escola. (BELTRÃO; ALVES, 2009, p. 126)

Embora estes debates tenham surgido mais freqüentemente a partir dos anos de 1990, é inegável a participação de outros agentes, além dos governos e das agências reguladoras de combate a pobreza no mundo e às questões da educação, sobretudo de mulheres carentes.

A Igreja católica, na primeira metade do século XX, em especial aqui no Brasil, trazia à tona novos modelos de educação popular para estas mulheres, comprovando que elas também poderiam estar à frente destas questões.

\section{Litoral Sul Paulista e Vale do Ribeira: Ações Comunitárias}


Com a adesão das indústrias por mulheres à força de trabalho na sociedade paulistana, ainda no século XIX, surge um novo tipo de mulher, com novas formas de pensar e agir, a trabalhadora. Os centros urbanos que se formavam se constituíam de uma estrutura ocupacional diversificada e dinâmica, mas ainda assim sujeitas à repressão dos valores masculinos.

Em São Paulo, no início do século XX, o trabalho informal também ganha sua importância, como a venda de produtos hortigranjeiros, costura e fabricação de doces e artesanato; nas fábricas, parte destinada a costura da sacaria vai para as mulheres. Enquanto nas cidades do litoral sul paulista predominava as atividades terciárias, como o comércio e os transportes, na capital o interesse estava nas indústrias como as voltadas para a alimentação e têxteis, empregando centenas de mulheres, as comunidades rurais mais afastadas dos centros compunham uma histórica paralela, quebrando a noção de totalidade da história, de sentido único. Embora o Brasil neste período tenha sido dinamizado pelo chamado "ruralismo pedagógico", em que o homem do campo conseguiria finalmente adquirir um estudo, o Estado Novo não parece alcançar os locais mais afastados do litoral sul paulista, geograficamente distante da arena política do momento, principalmente das mudanças que ocorrem a partir de então no campo da educação com o movimento da Escola Nova, um movimento que ganhou impulso na década de 1930, após a divulgação do Manifesto da Escola Nova (1932). Nesse documento, defendia-se a universalização da escola pública, laica e gratuita.

Nestas comunidades rurais nada parecia acompanhar tais movimentos deste crescimento social, e suas mulheres mantinham seus modos de vida tais como aprenderam das gerações anteriores, somente adquirindo identidade social através do casamento e do reconhecimento masculino como mulher-mãe. Essa imagem doméstica da mulher, sem capacidade política de se auto guiarem, cuidando apenas de seu lar, dos animais domésticos e das plantações que trariam sua subsistência se contrastava com a mulher que se integrava 
nas fábricas, ela se opunha a uma nova mulher cidadã apta para a vida particular e pública.

Para Dussel (1995) e sob a ótica da filosofia da libertação, verdades impostas e absolutas, principalmente na transmissão de saberes, negam a natureza do outro. Isto deve ser radicalmente combatido, dando lugar ao conhecimento-linguagem-alteridade, ou seja, escutar e acolher, a palavra compartilhada, o enriquecimento mútuo. É um processo educativo, uma forma continuada de ensinar e aprender, talvez instável num primeiro momento, mas que respeita, sobretudo, a existência.

O surgimento de políticas públicas voltadas para a educação se inicia nos meios urbanos, redirecionando o desenvolvimento brasileiro para o setor urbano-industrial, e mesmo com uma pressão popular a partir de 1945 para uma equidade no ensino, os setores mais carentes da população, principalmente nos meios rurais, pano de fundo deste trabalho, ficaram de fora de uma democratização escolar:

As novas exigências da industrialização e dos serviços urbanos influenciaram os conteúdos e a expansão do ensino. Porém, como a expansão do capitalismo não se fez de forma homogênea em todo o território nacional, a maior expansão da demanda escolar ocorreu nas regiões onde as relações capitalistas estavam mais avançadas. (BELTRÃO; ALVES, 2009, p.130)

O surgimento de movimentos populares que surgiram neste período e as ações educativas que a fizeram as mulheres refletirem sobre suas condições trouxe "um novo olhar" sobre os valores inseridos na sociedade e, sobretudo, no campo da educação, pois que a escola formal desconsiderava a educação para mulheres pobres. Cabe aqui a citação de ações comunitárias que se justificam por si mesmas, espaços de consciência e de respeito por esta mulher, indispensáveis para o crescimento de suas práticas sociais, livres e criativas. 
Em se tratando da educação popular, Brandão (2006) aponta que educação popular nasce junto às primeiras formas e de organização das pessoas, sendo parte de seus ritos sagrados, costumes e trabalhos. A educação popular organizada, no Brasil, ganha força e corpo a partir de 1950, mas sabe-se que muito antes, ela já caminhava em pequenos núcleos comunitários, nos meios rurais, a exemplo das ações por parte da Igreja católica.

Um movimento de grande importância social e educativa para as mulheres e que ocorreu no litoral sul paulista surgiu em 1929, intitulado Assistência ao Litoral de Anchieta (A.L.A). Tal movimento proposto pela Igreja católica traz à tona determinadas formas escolares e o papel social desempenhado pelas mulheres envolvidas neste processo - educadora-educanda -, enfatizando a importância da representação feminina em seu meio: "Lançava-se assim um apelo às santistas da classe média, para que se tornassem educadoras de outras mulheres. Implantava-se a EDUCAÇÃO DA MULHER PELA MULHER” (ROLIM, 1998). A Igreja católica, portanto, tem uma participação ativa na educação dita popular destas mulheres, produz novas formas escolares e enfatiza a importância da representação feminina no seu meio. Dentre os ensinamentos que estas mulheres recebiam na A.L.A.: o ensino das letras, educação moral e cívica, canto orfeônico, corte e costura, como se comportar em sociedade, educação sexual e preparo para o casamento; puericultura e tratamento de doenças; cuidados com a terra e criação de animais domésticos; o trato com os alimentos e o preparo adequado das refeições.

Este movimento surge com o intuito de levar uma educação cristã a estas comunidades carentes, bem como instruir as famílias por melhorias de condições sanitárias e de padrão de vida. Destinado à formação de líderes comunitárias, evidencia a trabalho da Igreja Católica em um momento em que as ações do Estado não alcançavam tais regiões. Faz-se necessário destacar, primeiramente, a prática social da mulher nesse contexto para identificá-la como um sujeito que se torna protagonista do seu dizer e do seu fazer. Nesse senti- 
do, essa mulher oportuniza a si mesma um caminho para a Exteriorização do ser, em busca da Alteridade num meio ainda opressor (DUSSEL, 1995).

O Encontro de Mulheres, que acontece no Vale do Ribeira por meio da Congregação Jesus Bom Pastor, localizada em Eldorado Paulista (SP) retrata muito esta ação comunicativa. Por dez anos este Encontro passou a debater sobre os problemas que as mulheres ainda enfrentavam nos anos 1990: preconceito, falta de oportunidades, opressão dos homens, falta de conhecimento que gerava doenças, trato com crianças e religiosidade. Na reflexão destas práticas educativas, Dussel citado por Grolli (2004, p. 93) argumenta que "é na vida diária do pobre, da mulher, do velho e da criança, que a justiça está ausente: a justiça que se constitui na exigência fundamental da dignidade humana”. Os Encontros que acontecem todo o mês acontecem em várias comunidades. O objetivo é refletir os acontecimentos que se deram naquele período após cada evento. Em cada encontro se discute um tema e, a partir dele, novos trabalhos nas comunidades são inseridos. As religiosas sempre trabalharam pela conscientização destas mulheres, e nas próprias cartilhas veiculadas no decorrer do tempo, procuraram refletir e auxiliar as mulheres que tentavam buscar uma emancipação.

A educação popular tem um compromisso social com a construção do poder popular, na formação de sujeitos com dignidade. As ações aqui exemplificadas parecem comprovar que as mulheres adquirem uma maior autonomia e consciência de seu papel de gênero, participa mais ativamente do mundo e do trabalho, conquista aos poucos seus direitos civis e de acesso à cultura, ou seja, ampliam seu espaço social, passa a confiar mais em si mesma e nas suas ações perante a família e comunidade.

Os estudos do passado sobre a relação entre mulher e religião apontam a cumplicidade da discriminação contra a mulher que parte da Igreja católica e do pensamento social. A rearticulação da Igreja sobre seu papel na sociedade e a importância da força que têm no âmbito familiar traz um novo modelo de socialização nas famílias e 
procura romper com o pensamento medieval de que a mulher deve aceitar todo tipo de violência, de sua condição de pobreza e de subordinação ao marido em nome do sofrimento e da cruz de Cristo.

\section{Dussel e a Libertação feminina}

O trabalho da filosofia da libertação de Dussel com o ser oprimido tem base no contexto de uma vida prática concreta, que além de simplesmente ser solidário com o outro, busca a troca e o aprendizado mútuo. Esta presença prática está dentro de movimentos populares, antirracistas, feministas e deve ser entendida como um processo de libertação conjunta, tanto do ser oprimido quanto do opressor, segundo esta filosofia.

Considera-se neste caso a mulher pobre e analfabeta e de como esta mulher é vista do ponto de vista de uma filosofia da libertação, de como alcança sua Exterioridade, e não do ponto de vista da Totalidade do meio, de uma possível "aceitação" ou "solidariedade", seja através de uma simples ajuda ou de um sentimento de pena, que às vezes surge em próprio meio de origem, como historicamente a subordinação da mulher diante do homem (DUSSEL, 1995). Desse modo, não poderá existir uma libertação quando esta parte somente de uma das partes, daquela que se considera superior, porque sucedendo de forma totalitária a libertação desta mulher, que passa a lutar por sua dignidade e por conseqüência, de seus direitos, inclusive pelo aprendizado, se torna limitada, neopragmática, negando toda uma realidade racional existente.

Sob a ótica da Filosofia da Libertação, verdades impostas e absolutas, principalmente na transmissão de saberes, negam a natureza do Outro. Estabelecer uma relação "pessoa-a-pessoa" ou "face-aface" não é somente agir com caridade, mas agir se reconhecendo no Outro, formando em seu conjunto uma ética comunitária: "O ponto de partida é o pobre ou oprimido, que trabalha dentro de suas condições corporais de sofredor e necessitado" (DUSSEL, 1995, p. 127). 
Faz-se necessário explicitar a concepção dos trabalhos educativos destes movimentos populares que objetivam a libertação desta mulher e sua inserção social, não somente a mulher educanda, mas também da mulher enquanto educadora que, na visão de Dussel (1995), nos remete a uma filosofia da libertação, num processo que passa do não-ao-Outro para o sim-ao-Outro, não como forma de simples aceitação do Outro, mas através da "consciência ética" na práxis libertadora.

Infelizmente, um dos traços da autoperpetuação de uma consciência oprimida é sua falta de consciência de ser oprimida (MANANZAN, 1994, p. 75). De certa forma, estas mulheres passam a involuntariamente colaborar com a opressão, com o descaso da sociedade e de seu próprio meio e reduto familiar. Devido à sua falta de consciência, acaba por aceitar sua condição de subordinação e de exploração.

Dessa forma, este trabalho enfatiza que só haverá entendimento do que seja um determinado estudo sobre esta mulher brasileira desvalida de recursos educacionais, se esta for vista enquanto sujeito em busca de sua libertação, e não como um objeto de estudo de uma simples "reflexão" externa, e isto só é possível através de uma presença prática concreta do pesquisador na relação imediata do face-aface, o que para Dussel é o ponto de partida da libertação.

Rolim (1998) afirma que neste processo educativo proposto e vivenciado pelos participantes da A.L.A. surgiram:

Outras formas educativas, descontínuas e instáveis, que se coadnunam com o que Paulo Freire denomina de trabalhos educativos, e que foi vivenciado nas três sedes da A.L.A. Estas formas educativas afirmam, num enfoque antropológico, que o cerne mais íntimo do homem é a existência (ROLIM, 1998, p. 177).

Neste despertar e neste encontro consigo mesma, a mulher que consegue se libertar por meio de uma educação popular recria seus caminhos. Nos desabafos, nas entrevistas, nas circulares religiosas e nas correspondências trocadas entre as educandas que retor- 
navam para suas comunidades e as educadoras, há novos valores, na crítica a uma sociedade androcêntrica. Para a Igreja que realizou estes movimentos de educação popular, a garantia de que houve o fortalecimento do direito da mulher a uma participação mais ativa na sociedade, surge de forma notável, além de ter ajudado as comunidades desta região e a própria Igreja a se desenvolver mais humanamente - construindo um modelo novo de sociedade e de Igreja, baseado nos princípios de igualdade, justiça e fraternidade.

Outros programas voltados para a educação popular para mulheres no litoral sul de São Paulo são citados aqui: o das Irmãs de Bom Jesus Pastor, conhecido como Irmãs Pastorinhas que atuam no Vale do Ribeira (São Paulo) desde a década de 80, levando para as comunidades a importância do meio ambiente, da saúde na família e o letramento. Em atenção às mulheres, procura dar assistência e orientações acerca dos valores postos na sociedade, de família, de estudos e de cidadania; e o Núcleo de Extensão Comunitária (NECOM) da Universidade Católica de Santos, fundado na década de 90 e que através de alunos de diversos cursos, como Pedagogia e Psicologia, contribui para a formação de cidadãos comprometidos com o bem estar social da comunidade onde vivem e intervindo através da educação, por vezes informal, para a organização e melhoria de condições de vida da população. Quanto às mulheres, o NECOM realiza diversos trabalhos: orientação psicológica às mulheres, alimentação e qualidade de vida, gravidez na adolescência, terceira idade e letramento.

\section{Mulher, Memória e História Oral}

Perrot (1989) aponta que no século XIX e ainda no início do século XX, nos arquivos públicos, havia somente a história de homens narradas por homens e que calavam as mulheres. A história destas mulheres singulares estava guardada nos arquivos familiares, nas cartas, fotografias, diários que preservavam das histórias de sua 
família e de suas práticas sociais. Arquivos estes na maioria das vezes destruídos pelo tempo, pelas gerações futuras, pelas mudanças causadas no seio familiar, pela indiferença:

Muitas mulheres, de resto, pressentindo a indiferença, se antecipavam a ela "colocando suas coisas em ordem", isto é, destruindo seus cadernos íntimos, temendo a incompreensão ou a ironia de seus herdeiros. (PERROT, 1989, p. 12)

Este consentimento ao silêncio imposto pela sociedade à mulher, ocultando sua vida, fazendo com que ela se negue a si mesma, não é privilégio somente de uma classe social mais abastada neste período, mas também das mulheres das classes populares. Como não poderiam exercer a escrita, pois muitas não conheciam as letras, guardavam suas memórias através de pequenos objetos, roupas de cama, mesa e banho, desenhos e retratos, afinal, são relíquias que só elas sabem o preço.

Conhecer a história da mulher excluída, a mulher do povo, é narrar através dos historiadores que só se fala dela quando o assunto é a histeria ou a as algazarras contra os comerciantes que cobravam mais caros pelos alimentos. Perrot (1989, p. 11) afirma que a história das mulheres ao longo do tempo se detém pouco sobre a mulher em sua singularidade, em seu dia-a-dia, enfatizando mais a mulher enquanto entidade coletiva que se desloca fora de seus territórios que lhe foram reservados.

Está certo que determinadas representações da mulher são construções culturais e históricas, muitas vezes vistas por elas como algo natural, inclusive a pobreza. Naturalizando-se a pobreza, como algo quase que "hereditário", passada de geração em geração, seu combate torna-se mais difícil, porque esta pobreza está arraigada no comportamento e na mente. Por não terem a educação necessária, são duplamente culpadas porque, além de não saber como desviarse da pobreza, ainda "transmitem" a ignorância e a pobreza para seus filhos (GOUVÊIA, 2008). 
Reconstituir a memória coletiva através da história oral é entender como esta memória é em verdade um fenômeno construído coletivamente, embora submetido a flutuações e mudanças (POLLAK, 1992). Portanto, as histórias de vida de mulheres marginalizadas são narradas de forma factual, ou seja, de maneira não organizada, com alterações de datas e acontecimentos, denotam que tais relatos são característicos de um grupo social com um grau educacional muito baixo, com pouca experiência profissional ou política. Através de documentos, relatórios, cartas e entrevistas, estas histórias de vida se tornam instrumentos privilegiados de avaliação, pois que imprimem as características culturais do grupo e seu modelo de socialização.

A história oral destas mulheres, a experiência narrada através das cartas entre as educadoras e as educandas, os relatos de pessoas das comunidades registrados através de atas de reunião realizadas nas paróquias locais, as fotografias e as entrevistas realizadas naquela época evidenciam que certos grupos sociais passaram por lutas, mas que também participaram de relações sociais determinadas por eles mesmos: "[...] a história real é construída por homens reais" (VIEIRA, PEIXOTO \& KHOURY, 1989).

Se os registros das mulheres estão ligados à sua condição, vivenciadas na família e na sociedade, o mesmo pode ocorrer em suas narrativas do passado. No teatro da memória a mulher inferiorizada pelo seu meio social partilha acontecimentos que lhe foram marcantes e se torna portadora da vida privada para as gerações futuras, porém, as formas de linguagem empregadas estariam relacionadas aos acontecimentos do cotidiano, provavelmente desqualificadas de um tipo de comunicação moderna ou ao sucesso de uma escrita erudita, mas que carrega na memória acontecimentos cheio de significados.

Através das entrevistas e dos relatos que formam a memória destes grupos percebe-se como determinados movimentos sociais que surgem alteram o cotidiano destas mulheres, como se viam e agora como passam a se reconhecer, como suas rotinas mudaram e, 
principalmente, como organizam estas lembranças individualmente e coletivamente.

\section{A pesquisa e seus avanços: primeiros resultados das análises}

Ao analisar a fala de historiadores e educadores, no campo desta pesquisa, aponta-se que houve grande avanço nos debates acerca da educação popular feminina, principalmente na segunda metade do século XX. Soihet e Pedro (2007) argumentam que o desenvolvimento de novos campos de pesquisa sobre mulheres bem como a história das mentalidades e a história cultural promovido pela Escola dos Annales, surgida em 1929, trouxe mudanças significativas nas últimas décadas, embora de maneira tímida. A partir da segunda metade do século XX, não somente questões de educação para mulheres, mas as pesquisas começam a se debruçar sobre temáticas e grupos sociais até então excluídos historicamente, como os operários, camponeses, escravos, gênero, etc., pluralizando-se os objetos de investigação histórica. Com a terceira geração dos Annales em 1970, as mulheres se tornam objetos de pesquisas e sujeitos da história.

Pelo caminho das pesquisas sobre mulheres e educação, não poderia deixar de serem citadas historiadoras como Mary Del Priore, Vanilda Paiva e Michele Perrot, historiadoras que buscam evidenciar a questão do gênero, haja vista, em seus estudos mostram outra concepção da mulher substituindo a vítima e oprimida por uma mulher rebelde, ativa e resistente, desmistificando a visão das mulheres como insignificantes e frágeis.

Esta pesquisa traz em seu arcabouço teórico documentos e memórias. A história oral também deve ser entendida como uma experiência humana, de determinado grupo social. Estas experiências serão recuperadas agora com "um novo olhar", com o intuito de alimentar o presente e o futuro. Faz-se necessário conhecer os cami- 
nhos traçados pelas mulheres inseridas nestas comunidades para que se conheça não somente o que está sendo representado por elas, mas por que está sendo representado daquela forma.

Daí a importância dos estudos do gênero feminino e da educação para mulheres, além de como a Igreja católica interferiu nos modos de vida de mulheres dos meios rurais por meio da educação e de como estas se organizaram em suas comunidades. Sem dúvida, elas passaram por um processo de disciplinarização que permeou toda a atividade social do grupo, desde as festividades até a família e o trabalho. Neste sentido, conhecer as maneiras de como uma comunidade se organiza significa conhecer os modos de poder envolvidos no processo. Em contrapartida, as mulheres também modificaram o processo social na qual estavam inseridas (pressões determinantes), trazendo a importância da singularidade dos sujeitos em suas práticas sociais.

Vieira et al. (1989) apontam que existem vários processos históricos que caminham simultaneamente, trazendo a história como um campo de possibilidades. Fato é que mulheres ainda são excluídas do âmbito escolar, e enquanto isto ocorrer haverá projetos, utópicos ou não, de superação social. Na existência do pensamento da mulher pobre como "dona do lar" e "pouco pensante", a esperança se torna uma força vital para a sobrevivência. Nesta miséria concreta da falta de conhecimento, as ações sociais se tornam um caminho alternativo, uma forma de combater a ignorância da opressão e de que homens e mulheres são desiguais quando se trata de justiça social. Infelizmente, ainda há resquícios deste tipo de pensamento que sobrevive de culturas anteriormente impostas e de maneira que não se pode crer, nas "sociedades modernas", mas a esperança permanece.

\section{Considerações finais}

Diante da existência de idéias preconcebidas sobre a mulher e as limitações impostas a elas, sobretudo no campo educacional, esta 
pesquisa parte em busca de apresentar a questão do gênero feminino, comparando os conceitos de integração e inclusão no que tange a educação, na busca do entendimento por esta mesma mulher no que diz respeito à sua identidade no contexto social brasileiro, apresentando os princípios humanísticos e éticos que justificaram as propostas de educação popular que se fortalece no início do século $\mathrm{XX}$, evidenciados por parte de ações da Igreja católica.

Nenhuma forma de ensinar é homogênea, e a comunidade científica deve considerar este aspecto, pois que novas formas de exercer a educação, principalmente às voltadas para as camadas populares têm sua origem em um passado de lutas pela sobrevivência e na busca pela cidadania, sem contar o valor que deve ser dado à mulher neste meio. A formação do ser social em nosso país é peculiar e deve ser entendida, considerada e respeitada pelos agentes que viabilizam projetos de educação, não buscando uma "padronização" das formas escolares, mas respeitando a origem cultural e de recursos dos envolvidos no processo.

No que trata da profissão docente todo aprendizado é válido e pode colaborar na transformação do meio. Os saberes e o conhecimento de práticas utilizadas por outros sujeitos ajudam na percepção e no entendimento de que uma mudança de hábitos por parte do professor é possível e que a educação dita "popular" tem seu espaço e seu valor diante do contexto sócio-político da atual sociedade brasileira.

Este trabalho poderá contribuir para o entendimento de que formas particulares de ensino popular, sobretudo as que são direcionadas para o gênero feminino no combate ao analfabetismo, podem ser aplicadas utilizando-se do que já foi proposta por outros agentes sociais, neste caso a Igreja católica. Faz-se necessário conhecer os caminhos utilizados por estes movimentos e do que estes contribuíram para a formação do ser social e da edificação das comunidades envolvidas no projeto. Além de tudo, a importância deste estudo é partir em busca do entendimento de que se faz necessário produzir uma consciência de reeducação e de reconscientização na tarefa de 
trabalhar com o Outro, ou seja, a autonomia e a liberdade de exercer a educação sem alienações opressoras, o que gera enriquecimento mútuo entre o educador e o educando.

Para concluir será importante identificar questões que se fazem surgir no próprio campo da pesquisa reconhecendo o avanço de estudos desta relação mulher pobre-educação popular no Brasil, somente assim esta mulher terá chance de expressar a sua voz. Neste intuito, o pesquisador não poderia pautar suas pesquisas sem entender tais modelos impostos e sem a convivência com os diversos movimentos de educação popular que surgem a cada dia nas comunidades brasileiras.

Buscar e descobrir, através das hipóteses, os fatos e as relações que constituíram este processo libertador, é ter em mente que tais hipóteses estão relacionadas aos "mil conhecimentos externos", ou seja, o pesquisador traz novos conhecimentos com os quais as fontes dialogam. Como isto pode ocorrer constantemente durante a pesquisa, as hipóteses, assim como a problemática poderão sofrer mudanças: "A partir desse diálogo o pesquisador vai formular ou reformular seus próprios conceitos, verificar que outros agentes devem abordar e, consequentemente, que registros buscar" (VIEIRA, et al., 1989).

Conclui-se que os investimentos na alfabetização para as mulheres trazem retornos sociais altos: melhora a saúde das famílias e traz uma conscientização do dever de motivar seus filhos também a estudar. Mulheres recém-alfabetizadas melhoram os indicadores de desenvolvimento e, portanto, todos os cidadãos, instituições e organismos governamentais deveriam estar comprometidos para a alfabetização destas mulheres que tanto tem sofrido com a opressão ao longo da história. Deveria ser prioridade, não apenas para ajudar esta mulher a distinguir preços nos comércios ou ler rótulos de medicamentos, mas sim, distinguir a opressão em que ela própria vive, e assim conscientizar-se de seu importantíssimo papel social. 


\section{Referências}

BANCO MUNDIAL. Informe sobre el desarrollo mundial 1990: la pobreza. Washington, DC: Banco Mundial, 1990.

BELTRÃO, K. I.; ALVES, J. E. D.: A Reversão do Hiato de Gênero na Educação Brasileira no Século XX. Cadernos de Pesquisa, v. 39, n. 136, jan./abr. 2009. Disponível em: <http://www.scielo.br/ pdf/cp/v39n136/a0739136.pdf> Acesso em: 18 de fev. 2019.

BRANDÃO, C. R. O que é educação popular. São Paulo: Brasiliense, 2006. (Coleção Primeiros Passos, n. 318)

DUSSEL. E. Europe, modernity and eurocentrism. Nepantla: Views from South, v. 13, p. 465-478, 2000. Disponível em: <http://www. unc.edu/ aescobar/wan/wandussel.pdf > Acesso em: 17 de out. de 2018.

Paulo: Paulus, 1995.

Filosofia da Libertação: Crítica à ideologia da exclusão. São

FARAH, M. F. S. Gênero e políticas públicas. Estudos Feministas, Florianópolis, n. 12, v.1, p. 47-71, jan/abr. 2004.

GONÇALVES, A. Desenvolvimento Econômico da Baixada Santista. Santos: Edit. Universitária Leopoldianum, 2006.

GOHN, M. G. Movimentos Sociais e Educação. Questões da Nossa Época. 2 ed. São Paulo: Cortez, 1994. (Questões da Nossa Época, 5)

GOUVÊIA, L. A. V.N, NOMA, A. K. Educação Feminina e Trabalho a Agenda Política de Redução da pobreza do Banco Mundial e Cepal. In: VI Seminário do Trabalho, 2008, Marília. Disponível em: < http://www.estudosdotrabalho.org/anais6seminariodotrabalho/led anabucogouveaeameliakimikonoma.pdf $>$ Acesso em: 06 dez. 2018.

GROLLI, D. Alteridade Feminino. São Leopoldo: Nova Harmonia, 2004.

MANANZAN, M. J. Socialização Feminina: mulheres como vítimas e colaboradoras. In: FIORENZA, E. S. (Org.). Violência contra a mulher. São Paulo: Vozes, 1994. (Concilium/252 - 1994/2: Teologia Feminista).

PAIVA, Vanilda P. Educação Popular e Educação de Adultos, Contribuição à História da Educação Brasileira. In: Temas Brasileiros II. São Paulo: Loyola, 1973.

PEREIRA, M. A. F. Assistência ao Litoral de Anchieta e a experiência de educação de líderes femininas (1939-1942). In: WERLE, Flávia Obino Corrêa (Org.). Educação Rural. Brasília: Líber Livro, 2010. 
PERROT, M. Práticas da Memória Feminina. A Mulher e o Espaço Público. Revista Brasileira de História. v. 9, n. 18, p. 9-28. São Paulo: Ed. Marco Zero, 1989.

POLLAK, M. Memória e Identidade Social. Estudos Históricos. Rio de Janeiro, v. 5 n.10, 1992, p.200-212.

PRIORE, M. del.; BASSANEZI, C. História das mulheres no Brasil. 2. ed. São Paulo: Contexto, 1997.

ROLIM, L. C. Semeadoras da Esperança - "A.L.A. - Uma Forma de Educar”. São Paulo: Loyola, 1998.

SOIHET, R.; PEDRO, J. M. A emergência da pesquisa da história das mulheres e das relações de gênero. 2007, vol.27, n.54, pp.281300. Disponível em: < http://www.scielo.br/scielo.php?pid=s010201882007000200015\&script $=$ sci_abstract\&tlng=pt $>$. Acesso em: 27 mar. 2019.

VIEIRA, M. P. A., PEIXOTO, M. R. C.; KHOURY, Y.M. A. A Pesquisa em História. São Paulo: Ática, 1989. 